\title{
Estudo bibliométrico da produção científica sobre Políticas de Indexação no Banco de Teses e Dissertações da CAPES
}

\author{
Valdenise César Garcia \\ Universidade Federal do Pará, Biblioteca Central, Belém, PA, Brasil \\ valdenise.p@hotmail.com \\ Franciele Marques Redigolo \\ Universidade Federal do Pará, Faculdade de Biblioteconomia, Belém, PA, Brasil \\ francieleredigolo@gmail.com \\ Alegria Célia Benchimol \\ Museu Paraense Emílio Goeldi, Belém, PA, Brasil \\ alegria.benchimol@gmail.com
}

DOI: https://doi.org/10.26512/rici.v11.n3.2018.10459

Recebido/Recibido/Received: 2018-05-07

Aceitado/Aceptado/Accepted: 2018-07-03

Resumo: Trata-se de uma pesquisa descritiva de caráter quali-quantitativo, cujo objetivo geral foi realizar um levantamento da produção científica sobre a temática política de indexação no Banco de Teses e Dissertações da CAPES, sem período específico, a fim de apresentar um panorama das pesquisas realizadas sobre o tema e contribuir com novos estudos tanto para área de Tratamento Temático da Informação quanto para novos pesquisadores que pretendam investigar o assunto futuramente. 0 método adotado foi o bibliométrico e os resultados evidenciam que ainda há pouca publicação relativa à temática políticas de indexação e que os trabalhos existentes estão concentrados na região Sudeste, especificamente na Universidade Estadual Paulista, campus Marília. Tal constatação demonstra a necessidade de mais estudos e discussão sobre o tema em diferentes instituições e realidades.

Palavras-chave: Bibliometria. Indexação. Política de indexação.

\section{Bibliometric study of the scientific production on Indexing Policies in the Bank of Thesis and \\ Dissertations of CAPES}

Abstract: It carries out a survey of the scientific production on the topic indexing policy in the Bank of Thesis and Dissertations of CAPES, without a specific period, with the purpose of presenting a panorama of the researches carried out on the subject and contributing with new studies both to the area of Thematic Treatment of Information as for new researchers who intend to investigate the subject in the future. This research is characterized as descriptive, with a qualitative-quantitative perspective, using bibliometric method. The results show that there are few publications related to indexing policies, and that the existing works are concentrated in the Southeast region of Brazil, specifically in the State University of São Paulo, Marília campus. This fact demonstrates the need for more studies and discussion on the subject in different institutions and realities.

Keywords: Bibliometrics. Indexing. Indexing policy.

Estudio bibliométrico de la producción científica sobre Políticas de Indexación en el Banco de Tesis y Disertaciones de la CAPES 
Resumen: Se trata de una investigación descriptiva de carácter cuali cuantitativo, cuyo objetivo general fue realizar un levantamiento de la producción científica sobre la temática política de indexación en el Banco de Tesis y Disertaciones de la CAPES, sin período específico, a fin de presentar un panorama de las investigaciones realizadas sobre el tema y contribuir con nuevos estudios tanto para área de Tratamiento Temático de la Información y para nuevos investigadores que pretendan investigar el asunto en el futuro. El método adoptado fue el bibliométrico y los resultados evidencian que aún hay poca publicación relativa a la temática política de indexación y que los trabajos existentes están concentrados en la región sudeste, específicamente en la Universidad Estadual Paulista, campus Marília. Tal constatación demuestra la necesidad de más estudios y discusión sobre el tema en diferentes instituciones y realidades.

Palabras-clave: Bibliometría. Indexación. Política de indexación.

\section{Introdução}

A indexação é um dos mecanismos utilizados para a organização e tratamento da informação, cujo processo permite a identificação do conteúdo dos documentos para dispô-los em bases de dados ou catálogos para posterior recuperação da informação por assunto. Todo esse processo envolve procedimentos, normas e utilização de instrumentos para nortear as atividades a fim de disponibilizar com eficiência e qualidade os recursos informacionais para os usuários.

Nesse contexto, a atividade de indexação é uma das ferramentas fundamentais nas unidades de informação, pois seu objetivo "é permitir a intermediação entre usuário e documento no momento de busca e recuperação da informação em um sistema de informação" (PIOVEZAN, 2015, p. 28).

Para Robredo (1978, p. 73), a indexação "é uma operação que permite representar o conteúdo de um documento, considerado como essencial, [...], com o objetivo de facilitar ao máximo o armazenamento ou memorização da informação nele contida, ou com a finalidade de classificação e recuperação".

Em uma perspectiva atual, Rubi (2009, p. 81), caracteriza o ato de indexar com mais precisão, ao afirmar que "a indexação diz respeito à identificação do conteúdo do documento por meio do processo de análise de assunto e à representação desse conteúdo por meio de conceitos". A referida autora, acrescenta ainda que os conceitos selecionados no momento da análise de assunto serão traduzidos em termos de uma linguagem documentária, cujo objetivo dessa linguagem é a intermediação entre o documento e o usuário no momento da recuperação da informação.

Assim expresso, o profissional da informação ao obedecer a algumas fases e reflexões permite "que a indexação tenha uma correspondência precisa com os termos pesquisados pelo usuário no sistema de informação, sejam em índices, bases de dados ou catálogos" (GONÇALVES, 2008, p. 22). 
A norma NBR 12676 (1992) da Associação Brasileira de Normas Técnicas, orienta a realização da atividade de indexação a partir de três etapas, a saber: exame do documento e estabelecimento do assunto de seu conteúdo, identificação dos conceitos presentes no assunto e tradução desses conceitos nos termos de uma linguagem de indexação.

De forma mais precisa, UNISIST (1981), Fujita (2003), Redigolo (2010) e Dias e Naves (2004) denominam a primeira fase da indexação de análise de assunto, cujo propósito é determinar o assunto do documento por meio de três momentos: leitura documentária, identificação de conceitos e seleção desses conceitos válidos para recuperação. Depois, os conceitos selecionados pelo indexador são traduzidos em termos controlados com o auxílio de linguagens documentárias, também conhecida como linguagem de indexação (FOSKETT, 1973; ROBREDO, 1978; CAVALCANTI, 1982; DIAS; NAVES, 2013).

Esses procedimentos, relativos à indexação, podem sofrer interferências, devido ser uma atividade que envolve julgamento (PINHEIRO, 1978; NUNES, 2004). Nesse sentido, Pinheiro (1978, p. 109) afirma que "indexar é um processo intelectual altamente subjetivo", de modo que, se não for realizado adequadamente pode afetar a qualidade da recuperação da informação e o sucesso do acesso aos documentos pelos usuários nas unidades de informações.

Desta forma, para minimizar a subjetividade do processo de indexação e orientar o profissional da informação quanto aos procedimentos a serem realizados referentes a essa atividade, de modo que sejam executados com precisão, é necessário que haja nos ambientes das unidades de informação a política de indexação.

A política de indexação, na concepção de Nunes (2004, p. 55), "é uma diretriz que explicita as escolhas técnicas (por isso política) que a biblioteca faz (e os bibliotecários precisam observar em suas rotinas), considerando fundamentalmente duas variáveis: o seu usuário e o seu acervo". Ou seja, a política de indexação define e estabelece os critérios e procedimentos que serão utilizados para a prática da indexação, de modo que servirá de "guia na tomada de decisões para otimização do serviço, racionalização dos processos e consistência das operações, como aponta Carneiro (1985, p. 222).

À vista disso, essa política consiste em um conjunto de diretrizes elaboradas com o propósito de orientar os profissionais de informação nas tomadas de decisões quanto à atividade de indexação, visando à padronização, ao aprimoramento e à qualidade da indexação e, por conseguinte, à satisfação dos usuários ao fornecer um resultado mais eficiente na recuperação da informação por assunto nos catálogos. No entanto, é um tema pouco explorado em território brasileiro. 
Assim, esta pesquisa, por meio de indicadores bibliométricos, tem por objetivo realizar um levantamento da produção científica sobre a temática política de indexação no Banco de Teses e Dissertações da CAPES, possuindo como objetivos específicos: a) identificar teses e dissertações que tratam sobre o tema, b) verificar os indicadores bibliométricos (nível de dissertação ou tese, distribuição temporal e geográfica, instituição, programas de pósgraduação, linhas de pesquisa e orientadores) nas teses e dissertações recuperadas e c) apresentar o cenário da produção científica nacional sobre política de indexação a partir das teses e dissertações do banco de dados da CAPES. Visto que o método bibliométrico tem auxiliado os pesquisadores na análise da produção cientifica de determinadas áreas do conhecimento ou sobre temáticas especificas, ao permitir que estes verifiquem, a partir da construção de indicadores de produtividade, o desempenho e crescimento dessas áreas ou temáticas.

\section{Produção científica sobre a temática política de indexação}

A política de indexação é um conjunto de diretrizes elaborada com o propósito de orientar os profissionais de informação nas tomadas de decisões no que se refere à atividade de indexação, visando à padronização, ao aprimoramento e à qualidade do serviço de indexação, além de, por conseguinte, a satisfação dos usuários ao fornecer mais eficiência na recuperação da informação por assunto nos catálogos.

Fujita (2012, p. 22) define política de indexação como um "conjunto de procedimentos, materiais, normas e técnicas orientadas por decisões que refletem a prática e princípios teóricos da cultura organizacional de um sistema de informação", ou seja, além de servir como guia para a orientação de processos de uma atividade específica como a indexação, é também considerada uma filosofia que reflete os interesses e os objetivos da unidade de informação no que concerne à organização e tratamento da informação para seus usuários.

Nesse sentido, para Fujita e Santos (2016, p. 62), baseando-se em Rubi (2008), a política de indexação pode proporcionar "a harmonização do acesso por assunto em catálogos e bases de dados, tornando explícitas as decisões relativas à indexação para a equipe de trabalho e para os usuários que realizem busca por assunto", pois a principal função de uma política de indexação é fazer com que as informações sobre os documentos, isto é, as suas representações, sejam dispostas nos catálogos com qualidade para que assim o usuário tenha acesso à informação desejada através da recuperação por assunto de forma rápida e precisa.

Diante da importância desse instrumento para a orientação da indexação nas unidades de informação, alguns autores brasileiros têm dedicado tempo e esforços em estudos sobre políticas de indexação, tanto em nível prático, direcionando pesquisas para a elaboração da 
própria política, quanto em nível teórico, ao conduzir investigações para o desenvolvimento e contribuição da área de Tratamento Temático da Informação, mais precisamente da indexação.

No entanto, as discussões e pesquisas sobre política de indexação ainda são poucas em nível nacional. Em 1985, Carneiro detectou essa ausência de estudos ao afirmar que a literatura sobre política de indexação era bastante rara (CARNEIRO, 1985). Aproximadamente quase 20 anos depois, Rubi (2004, p. 12), através de uma pesquisa bibliográfica, declara que "poucos autores trabalham com a política indexação". Nesse mesmo ano o professor Cláudio Omar Nunes, do Departamento de Biblioteconomia e História da Universidade Federal do Rio Grande (FURG), afirmou que "inexistem referências objetivas a políticas adotadas por bibliotecas brasileiras. Ou bem não são feitos estudos sobre tais políticas ou bem elas inexistem formalmente" (NUNES, 2004, p. 56).

Rubi (2008), destacou que uma das causas da ausência de estudos sobre a temática política de indexação por este longo período é, principalmente, a maneira "como a indexação é vista dentro da biblioteca: muitas vezes, somente como um processamento técnico que não necessita de procedimentos sistematizados para identificação de assunto, apenas de uma leitura rápida para identificar e extrair os termos para representar o conteúdo".

Lousada et al. (2011, p. 200) também teceram comentários a esse respeito, declarando que "as discussões acerca da política de indexação ainda não possuem forte presença na literatura, por essa razão, é fundamental o estímulo a novos estudos que venham a sanar essa lacuna na bibliografia", e mais recentemente Fujita (2016) enfatiza a necessidade de mais pesquisas sobre políticas de indexação devido à escassez de literatura sobre o tema.

Observa-se que os autores tratam da ausência de política de indexação tanto em plano teórico como empírico, o que acaba sendo uma consequência de um fato para o outro. No decorrer dos anos, como observado pelas citações acima, a ocorrência de estudos sobre políticas de indexação até este momento ainda não atingiu um patamar mais elevado, verificando-se ainda uma falta de referências relacionadas ao tema.

Contudo, vale ressaltar que Mariângela Fujita, a partir dos grupos de pesquisa, primeiramente no grupo de "Análise Documentária" e mais recentemente no grupo de "Representação Temática da Informação" ambos da UNESP, cujas atividades direcionaram estudos ao tema, bem como a orientação de diversos trabalhos que envolvem a temática Política de Indexação, permitiram uma produção significativa para área, e isso nos possibilita inferir que os discursos aos poucos estão sendo construídos sobre o assunto.

Dentre a produção dos grupos de pesquisa, destaca-se o livro Política de indexação para bibliotecas: elaboração, avaliação e implantação (FUJITA, 2016), e os seguintes autores 
que publicaram suas pesquisas em periódicos científicos: Rubi e Fujita (2006) que desenvolveram um estudo sobre o ensino de procedimentos de política de indexação para a educação a distância do bibliotecário; Fujita e Gil Leiva (2009) desenvolveram um estudo sobre as políticas de indexação latino-americanas; Rubi e Fujita (2010) pesquisaram a política de indexação na catalogação de assunto em bibliotecas universitárias; Redigolo, Dal'Evedove, Fujita e Boccatto (2012) pesquisaram elementos de política de indexação em biblioteca universitária da área médica; Rubi, Fujita e Boccatto (2012) elaboraram um estudo prévio para política de indexação em bibliotecas universitárias; Guim e Fujita (2016) discutiram política de indexação para bibliotecas escolares; Fujita e Santos (2016) também elaboraram um estudo sobre política de indexação em bibliotecas universitárias e Dal'Evedove e Fujita (2017) que desenvolveram um estudo sobre proposta de política de indexação em bibliotecas universitárias.

Assim, devido aos poucos estudos realizados sobre a temática política de indexação, esta pesquisa visa realizar um levantamento da produção científica a respeito do tema no Banco de Teses e Dissertações da CAPES, com a finalidade de apresentar um panorama das pesquisas realizadas sobre o assunto.

\section{Avaliação da produção e comunicação científica por meio da bibliometria no banco de teses e dissertações da CAPES}

A realização de estudos e pesquisas é fundamental para o desenvolvimento de qualquer sociedade e principalmente para a evolução da própria ciência, pois é a partir dessas pesquisas que soluções sobre determinados assuntos ou problemas são estudados e resolvidos. Contudo é por meio da comunicação científica que os resultados desses estudos são analisados, avaliados e legitimados pela comunidade científica, sendo posteriormente comunicados para outros pesquisadores e para a sociedade de modo geral.

Esse compartilhamento dos resultados das descobertas e troca de ideias entre os pesquisadores não é algo recente. Em seu artigo sobre evolução da comunicação científica até as redes eletrônicas, Pinheiro (2006) nos diz que a necessidade de comunicar os conhecimentos sobre as invenções era uma preocupação dos cientistas desde o século XVII, quando começaram a organizar as primeiras sociedades cientificas, como a Royal Society of London em 1660, com o objetivo de facilitar a troca de informações entre os pesquisadores.

A comunicação científica transmite o conhecimento científico, e como afirma Mueller e Passos (2000, p. 14), "o conhecimento científico é mais amplo e reflete resultados de uma área. Fatos e teorias propostos por um pesquisador devem ser submetidos ao exame crítico e a testes realizados por outros cientistas competentes e imparciais". Ou seja, por mais que 
estudos e ideias sobre qualquer área do conhecimento sejam publicadas e divulgadas amplamente, para serem consideradas conhecimento científico, precisam passar primeiramente por avaliação minuciosa de outros pesquisadores a fim de que o conhecimento possa ser revisado e validado, bem como "os resultados obtidos devem ser tão conclusivos que se tornem universalmente aceitos" (MUELLER; PASSOS, 2000, p. 14).

A avaliação feita por outros pesquisadores, também denominada revisão pelos pares ou avaliação às cegas, é essencial para legitimar e fornecer autenticidade ao conhecimento que é comunicado através dos canais de comunicação científica. Nesse sentido, Stumpf (2006, p. 48) diz que "a revisão pelos pares é um sistema complexo que reúne pessoas e atividades diferenciadas, mas complementares, para atingir um objetivo comum: julgar os originais submetidos pelos autores para publicação".

Meadows (1999) afirma que a comunicação dos resultados de uma pesquisa pode ser realizada por diferentes tipos de publicações e em diferentes momentos. Seu início se dá antes mesmo do final da pesquisa, começando pelas conversas face a face do projeto inicial, passando por relatos e apresentações orais em seminários, palestras em eventos, relatórios de projetos de pesquisa, relatórios verbais em congressos e conferências com o avanço da pesquisa, no qual a comunicação ainda é informal. Posteriormente, com o andamento da pesquisa, a publicação dos resultados (parciais ou finais) é concretizada através da comunicação formal em artigos de periódicos, capítulos de livros, livros especializados etc. 0 autor considera a tese como sendo um canal intermediário entre informal e formal.

Ainda de acordo com Meadows (1999), os artigos e livros científicos ainda são os métodos mais utilizados para publicação dos resultados da pesquisa por serem os itens mais lidos e citados, contudo é importante destacar também que esses resultados podem ser comunicados pelas Dissertações e Teses, oriundos dos programas de pesquisas de pósgraduação.

Como visto acima, existem diferentes tipos de publicações pelos quais as pesquisas podem ser conhecidas pela comunidade científica, sendo que os resultados podem ser comunicados para outros pesquisadores tanto pelos canais de comunicação formal ou informal como também divulgados para a sociedade à medida que as pesquisas avançam.

Dessa forma, a comunicação cientifica, ao viabilizar a comunicação dos resultados de novas pesquisas, permite consequentemente que novos pesquisadores saibam dos conhecimentos já produzidos sobre temáticas específicas e o que está sendo estudado atualmente em determinada área do conhecimento.

Nesse contexto, os estudos bibliométricos, a partir de métodos estatísticos, tem desempenhado papel importante no cenário da avaliação da comunicação científica ao 
permitir o mapeamento da produção científica e melhor compreensão desses processos de comunicação, pois "a Bibliometria engloba o estudo dos aspectos quantitativos da produção, disseminação e uso da informação registrada, desenvolvendo modelos e medidas matemáticas, com a função para elaborar previsões e apoiar tomadas de decisão" (MARICATO; NORONHA, 2013, p. 61).

Conforme Araújo (2006), a Bibliometria surgiu a partir da necessidade de avaliação das atividades de produção e comunicação científica, nesse sentido, Pereira, Ferreira Júnior e Hayashi (2013, p. 186) enfatizam que esta técnica permite:

Mapear e quantificar os processos de comunicação científica e entender a influência de autores e instituições na produção acadêmica. Ela possibilita traçar a evolução histórica do tema de pesquisa e as associações entre grupos de pesquisadores da área, suas filiações institucionais e as temáticas de seus estudos.

Benchimol (2015, p. 69), fazendo referência a Pritchard (1969), afirma que a Bibliometria é a "aplicação de métodos matemáticos e estatísticos aos processos de comunicação científica escrita" e acrescenta que suas leis "fornecem subsídios básicos de pesquisa, numa tentativa de controlar a explosão da informação e também capacitam os cientistas da informação a entender e analisar a literatura científica em diferentes aspectos" (FIGUEIREDO, 1973 apud BENCHIMOL, 2015, p. 68).

Desta forma, estudos têm sido desenvolvidos com o uso da técnica bibliométrica para a compreensão da produção científica de determinados temas (assuntos) do conhecimento. Um exemplo disso, é a obra Bibliometria e Cientometria: estudos temáticos (HAYASHI, M.; FARIA; HAYASHI, C., 2013), em que são apresentadas algumas investigações utilizando a abordagem bibliométrica para avaliar a produção de diferentes temáticas, a saber: Pizzani et al. (2013) analisaram a produção científica sobre o tema prematuridade disponível na bases de dados da BVS - Biblioteca Virtual em Saúde, Bello et al. (2013) utilizaram indicadores bibliométricos para analisar a produção científica sobre transtornos de aprendizagem na base de dados SCIELO - Scientific Electronic Library Online, enquanto Malaman, Sampaio e Souza (2013), analisaram o estado da arte acerca do tema processo de trabalho em Enfermagem, a partir da identificação da produção cientifica nacional e latino-americana, no período de 2000 à 2009, em revistas indexadas na Scielo e dissertações de mestrado e teses de doutorado disponíveis na base de dados do IBICT - Instituto Brasileiro de Informação em Ciência e Tecnologia.

Verifica-se, portanto, que o uso da Bibliometria para análise e avaliação da produção cientifica de temas específicos, como é o caso da política de indexação tratado neste estudo, torna-se importante, pois contribui para identificar, a partir de dados estatísticos, como está o 
desenvolvimento, desempenho e crescimento das pesquisas inerentes ao tema dentro da sua área do conhecimento.

\subsection{Banco de Teses e Dissertações da CAPES}

Diante do objetivo desta pesquisa, justifica-se o uso do banco de teses e dissertações da CAPES com a finalidade de avaliar a produção científica sobre Política de Indexação por meio das monografias disponíveis.

Deste modo, a Coordenação de Aperfeiçoamento de Pessoal de Nível Superior (CAPES) é uma fundação do Ministério da Educação (MEC) fundada em 11 de julho de 1951 por meio do Decreto no 29.741. Foi criada com a finalidade de "assegurar a existência de pessoal especializado em quantidade e qualidade suficientes para atender às necessidades dos empreendimentos públicos e privados que visam ao desenvolvimento do país" (CAPES, 2017a, não paginado).

Ao coordenar e avaliar o sistema brasileiro de pós-graduação stricto sensu (mestrado e doutorado), a CAPES vem atuando principalmente na busca pela qualidade dos Programas de Pós-Graduação em nível nacional e pela excelência das pesquisas e produção científica realizadas no âmbito desses programas, visando ao desenvolvimento e aperfeiçoamento da ciência no país, além de, consequentemente, ao progresso e crescimento nacional.

Neste sentido, a CAPES tem como competências:

Avaliação da pós-graduação stricto sensu, acesso e divulgação da produção científica, investimentos na formação de recursos de alto nível no país e exterior, promoção da cooperação científica internacional e indução e fomento da formação inicial e continuada de professores para a educação básica nos formatos presencial e a distância (CAPES, 2017a, não paginado).

Nesta perspectiva, com o propósito de comunicar os resultados das pesquisas realizadas no âmbito dos programas brasileiros de pós-graduação stricto sensu para a comunidade acadêmica e facilitar o acesso às monografias defendidas nesses programas, a CAPES vem disponibilizando por meio do seu Banco de Teses e Dissertações, sistema online, informações das dissertações de mestrado e das teses de doutorado defendidas nos programas de pós-graduação do país, como: ano da defesa, autor da monografia, orientador e coorientador, nome do programa e instituição em que foi defendida, área de concentração e do conhecimento cuja monografia pertence, entre outras informações (CAPES, 2017b).

Vale destacar, que os trabalhos inseridos no Banco de Teses anterior à Plataforma Sucupira, sistema gerenciador do Banco atualmente, eram disponibilizadas apenas as informações referenciais, já as monografias inseridas após a plataforma, são disponibilizados também os resumos e em alguns casos o link para acesso ao texto completo da monografia. 
O Banco de Teses integra aproximadamente 458.657 resumos de monografias (CAPES, 2010) e essa iniciativa começou em 2002, quando foram disponibilizados através da plataforma inicialmente 125.000 resumos de teses e dissertações defendidas de 1996 a 2001. Em um momento posterior, foram incluídas outras referências de trabalhos do período de 1987 em diante.

Diante disso, os usuários podem acessar as informações dos trabalhos através da pesquisa por autor, título e palavras-chave, mas também refinar os resultados por outros aspectos, como tipo de monografia, ano, autor, orientador, banca examinadora, área de conhecimento, área de avaliação, área de concentração, instituição, biblioteca, entre outros filtros necessários para melhor recuperar o trabalho.

Portanto, o Banco de Teses e Dissertações da CAPES, ao reunir em um único lugar as teses e dissertações brasileiras, propicia maior visibilidade à produção cientifica nacional, possibilita à comunidade científica obter informações sobre o que está sendo produzido em determinada área do conhecimento e também comunicar os seus trabalhos, bem como permite a novos pesquisadores ter uma visão panorâmica dos dados bibliométricos desses trabalhos ao visualizarem as instituições, autores, orientadores, anos, regiões e outras informações dos trabalhos para então produzir novas pesquisas.

\section{Percurso metodológico}

A fim de concretizar o objetivo proposto, esta pesquisa se caracteriza como descritiva, ao descrever os fatos e fenômenos observados sem interferência do pesquisador (PRODANOV; FREITAS, 2013), realizando uma análise quali-quantitativa. Fez-se inicialmente a revisão de literatura sobre as temáticas abordadas para, em seguida, usar o método bibliométrico.

Dada a importância da Bibliometria para mapear e verificar variáveis quantificáveis da produção científica de autores sobre determinadas temáticas a fim de compreender o processo de comunicação científica, este estudo fez uso de indicadores bibliométricos e procedimentos operacionais, conforme traçado por Guimarães et al. (2013) ${ }^{1}$ (ver quadro 1) para, primeiramente, extrair os dados das monografias recuperadas do Banco de Teses e Dissertações da CAPES e, em seguida, realizar a análise e interpretação dos dados.

\footnotetext{
${ }^{1}$ Os autores sistematizaram em um quadro a operacionalização das variáveis (indicadores bibliométricos e operacionalização) com base em Moran et al. (2010).
} 
Quadro 1: Indicadores bibliométricos e Operacionalização das variáveis

\begin{tabular}{|c|c|}
\hline Indicadores & Operacionalização \\
\hline Nível & Identificar e diferenciar dissertações e teses \\
\hline $\begin{array}{l}\text { Distribuição temporal e } \\
\text { geográfica dos trabalhos }\end{array}$ & Localizar trabalhos de acordo com o ano de produção e local \\
\hline Gênero* & Identificar o sexo do autor e do orientador (feminino ou masculino) \\
\hline $\begin{array}{l}\text { Vinculação dos autores e } \\
\text { orientadores }\end{array}$ & $\begin{array}{l}\text { Identificar os programas de pós-graduação e as instituições aos quais } \\
\text { os autores e orientadores estão vinculados }\end{array}$ \\
\hline Instituições & $\begin{array}{l}\text { Identificar em quais instituições de ensino superior os trabalhos foram } \\
\text { defendidos }\end{array}$ \\
\hline $\begin{array}{l}\text { Programas de pós- } \\
\text { graduação }\end{array}$ & $\begin{array}{l}\text { Identificar quais e quantos programas de pós-graduação } \\
\text { possibilitaram a realização de trabalhos no campo estudado }\end{array}$ \\
\hline Linhas de Pesquisa & Verificar a(s) linha(s) de pesquisa preponderante(s) \\
\hline Palavras-chave* & $\begin{array}{l}\text { Identificar os termos utilizados pelos autores, principalmente os mais } \\
\text { recorrentes }\end{array}$ \\
\hline Fomento* & $\begin{array}{l}\text { Identificar as agências de fomento e outros patrocinadores dos } \\
\text { trabalhos }\end{array}$ \\
\hline
\end{tabular}

Fonte: Guimarães et al., 2013, p. 197. Operacionalização das variáveis.

* Os indicadores gênero, palavras-chave e fomento não foram utilizados por não contemplarem os objetivos desta pesquisa.

Dessa forma, realizou-se o levantamento de monografias que tratam sobre políticas de indexação no Banco de Teses e Dissertações da CAPES sem especificar período (CAPES, 2017b). Foram utilizados os termos: "política de indexação" e "políticas de indexação" como estratégias de busca para recuperação das monografias.

Para a identificação e seleção das teses e dissertações com a temática desejada, levouse em consideração primeiramente o título das monografias, para então realizar a leitura dos resumos e de suas respectivas palavras-chave ${ }^{2}$, sendo feita em alguns casos leitura de partes das monografias. Assim, foram selecionadas teses e dissertações que de fato trataram sobre políticas de indexação, descartando aquelas em que o foco não é a temática, pois apenas mencionaram esporadicamente o tema.

Depois desta etapa, os dados das monografias (indicadores bibliométricos) foram sistematizados em planilha do Software MS Excel, em seguida tratados e dispostos em tabelas, quadros e gráficos para posterior análise e interpretação.

As etapas dos procedimentos metodológicos deste estudo podem ser visualizadas no quadro 2.

\footnotetext{
${ }^{2}$ Vale ressaltar que neste caso, as palavras-chave foram somente utilizadas para identificar as monografias com a temática política de indexação no Banco de Teses e Dissertações da CAPES, não sendo utilizadas como indicadores bibliométricos na análise das monografias recuperadas.
} 
Quadro 2: Etapas dos procedimentos metodológicos

\begin{tabular}{|l|l|l|}
\hline \multicolumn{1}{|c|}{ Etapas } & \multicolumn{1}{|c|}{ Procedimentos } & \multicolumn{1}{c|}{ Execução } \\
\hline 1a Etapa & Revisão de literatura & $\begin{array}{l}\text { Temas: Comunicação Científica; Política de Indexação e } \\
\text { Bibliometria }\end{array}$ \\
\hline 2a Etapa & Coleta de dados & -Fonte: Banco de Teses e Dissertações da CAPES \\
\hline 3a Etapa & Organização dos dados & $\begin{array}{l}\text { - Software MS Excel } \\
\text { - Quadros, tabelas e gráficos }\end{array}$ \\
\hline 4a Etapa & $\begin{array}{l}\text { Análise e interpretação dos } \\
\text { dados }\end{array}$ & Análise dos indicadores bibliométricos \\
\hline
\end{tabular}

Fonte: Elaborado pelas autoras (2017)

5 Interpretação dos dados: análise e avaliação bibliométrica da produção científica sobre Política de Indexação

A partir do levantamento da produção científica no Banco de Teses e Dissertações da CAPES sobre a temática política de indexação, foram recuperados 32 trabalhos. No entanto, após análise das monografias, verificou-se que apenas 23 tratavam de fato sobre o tema, sendo em seguida excluídas as duplicadas. Foram então selecionadas para análise somente 22 , como observados no quadro 3.

Quadro 3: Monografias recuperadas e selecionadas como corpus de análise do Banco de Teses e Dissertações da CAPES

\begin{tabular}{|r|c|c|c|}
\hline Menografias & $\begin{array}{l}\text { Quantidade de } \\
\text { monografias recuperadas }\end{array}$ & $\begin{array}{l}\text { Monografias que } \\
\text { tratam de fato } \\
\text { sobre política de } \\
\text { indexação }\end{array}$ & $\begin{array}{l}\text { Monografias } \\
\text { selecionadas para } \\
\text { análise, excluindo as } \\
\text { duplicadas }\end{array}$ \\
\hline $\begin{array}{l}\text { "Política de indexação" } \\
\text { "Políticas de } \\
\text { indexação" }\end{array}$ & 28 & 20 & 20 \\
\hline Total & 4 & 3 & 2 \\
\hline
\end{tabular}

Fonte: Elaborado pelas autoras. CAPES (2017b)

Das 22 monografias selecionadas, 19 (86\%) são dissertações de mestrado, das quais três são de mestrado profissionalizante, e três (14\%) são teses de doutorado, distribuídas no período entre 2004 a 2016, conforme tabela 1. 
Tabela 1 - Distribuição anual das teses e dissertações

\begin{tabular}{c|c|c|c|c}
\hline Ano & Mestrado Profissional & Mestrado & Doutorado & Total \\
\hline 2004 & 0 & 1 & 0 & 1 \\
\hline 2008 & 0 & 1 & 1 & 2 \\
\hline 2009 & 0 & 1 & 0 & 1 \\
\hline 2011 & 0 & 1 & 0 & 1 \\
\hline 2012 & 1 & 3 & 0 & 4 \\
\hline 2013 & 0 & 2 & 0 & 2 \\
\hline 2014 & 0 & 2 & 2 & 4 \\
\hline 2015 & 0 & 3 & 0 & 3 \\
\hline 2016 & 2 & 2 & 0 & 4 \\
\hline Total & $\mathbf{3}$ & $\mathbf{1 6}$ & $\mathbf{3}$ & $\mathbf{2 2}$ \\
\hline
\end{tabular}

Fonte: Elaborada pelas autoras (2017)

Como observado na Tabela 1 , a produção científica sobre a temática políticas de indexação no período entre 2004 a 2011 ainda era pouca, tendo em média apenas uma dissertação por ano, sendo que em 2008 verifica-se também a produção de uma tese. Esse fato retrata a continuidade de estudo sobre a temática realizada pela autora Milena Polsinelli Rubi, que defendeu sua dissertação e tese respectivamente em 2004 e 2008 no Programa de Pós-Graduação em Ciência da Informação na Universidade Estadual Paulista - UNESP, campus Marília.

A partir de 2012, percebe-se um aumento da produção, com média anual de três trabalhos, destacando-se os anos 2012, 2014 e 2016, com quatro monografias cada ano. O período de 2012 até 2016 apresenta 17 trabalhos, uma concentração de $77 \%$ da produção de todo período. Verifica-se com isso que o interesse pelo tema vem crescendo gradativamente conforme os anos. Em relação às instituições em que as 22 monografias foram defendidas, observa-se através da Tabela 2 os seguintes resultados:

Tabela 2 - Distribuição das Teses e Dissertações por Instituição de Ensino Superior

\begin{tabular}{c|c|c}
\hline \multicolumn{1}{|c|}{ Instituições de Ensino Superior } & Teses e Dissertações & Valor relativo (\%) \\
\hline UNESP & 11 & 50 \\
\hline UFPB & 3 & 13,6 \\
\hline UFPE & 2 & 9,1 \\
\hline UDESC, UFBA, UFSCar, UnB, UNIRIO, USP - \\
com 1 trabalho cada & 6 & 27,3 \\
\hline Total & $\mathbf{2 2}$ & $\mathbf{1 0 0}$ \\
\hline
\end{tabular}

Fonte: Elaborada pelas autoras (2017)

Nota-se que os trabalhos estão distribuídos em nove instituições de ensino superior. A maior concentração está na UNESP com 11 monografias defendidas (50\% do total), seguida 
pela UFPB e UFPE com respectivamente três e dois. As demais instituições contam apenas um trabalho cada: UDESC, UFBA, UFSCar, UnB, UNIRIO e USP.

A partir da distribuição geográfica das instituições, verifica-se que a maioria das monografias que tratam sobre políticas de indexação foram defendidas em instituições da região Sudeste (quatro instituições), com 14 (63\%) trabalhos no total, seguida pela região Nordeste (três instituições), com seis monografias (27\%), enquanto as regiões Sul e CentroOeste com apenas um trabalho ( $5 \%$ cada) nas instituições UDESC e UnB, respectivamente (Gráfico 1).

Gráfico 1: Distribuição das Instituições por regiões do Brasil

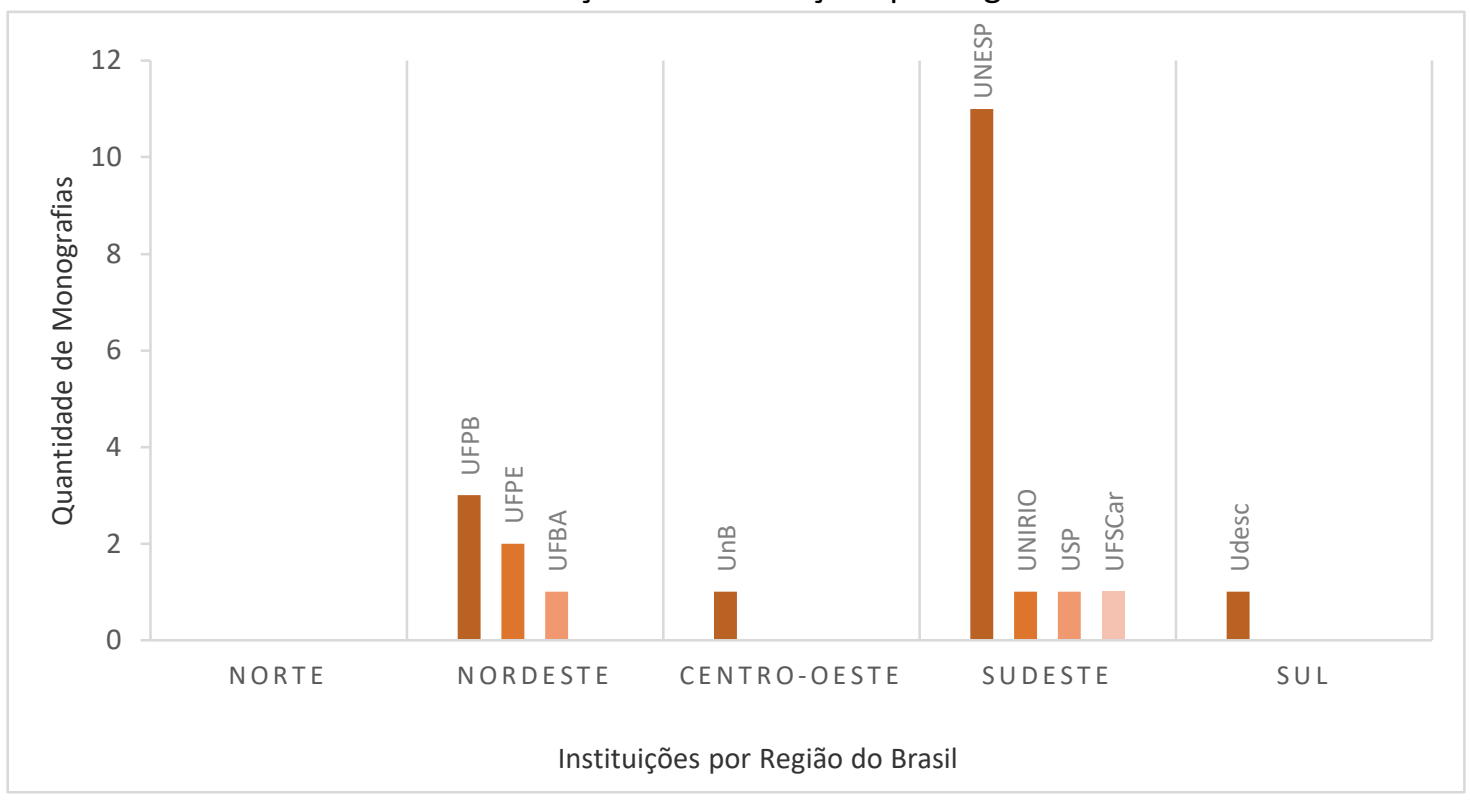

Fonte: Elaborado pelas autoras (2017)

Apesar das regiões Sudeste e Nordeste apresentarem quase a mesma quantidade de instituições produzindo trabalhos sobre políticas de indexação (4 e 3 respectivamente), a região Sudeste revela um número elevado de monografias (63\%), devido principalmente à alta produção da UNESP. Essa universidade tem concentrado um número significativo de docentes e discentes com interesse no tema, vinculados ao Programa de Pós-Graduação em Ciência da Informação, eixo temático Organização da Informação da linha de pesquisa Produção e Organização da Informação (UNIVERSIDADE ESTADUAL PAULISTA, 2017), o que tem contribuído para a criação constante de grupos e projetos de pesquisas, o que, consequentemente, tem elevado a produção científica sobre políticas de indexação nessa instituição e na região Sudeste. 
Não foram identificados trabalhos de instituições da região Norte (Gráfico 1). Essa situação se deve, principalmente, à ausência, até meados de 2016, de Programas de PósGraduação em Ciência da Informação na região com linhas de pesquisas para a temática Organização da Informação, englobando o Tratamento Temático da Informação e a própria indexação ou áreas similares (CAPES, 2017c). Vale destacar que, no final de 2016, foi criado o primeiro Programa de Pós-Graduação em Ciência da Informação da região Norte, vinculado à Universidade Federal do Pará, de modo que podem, futuramente, surgir novas pesquisas sobre a temática oriundas da região.

A investigação também revelou que as 22 teses e dissertações foram defendidas em cinco programas de pós-graduação, distribuídas em 12 linhas de pesquisa (Quadro 4), sendo que 18 trabalhos (82\%) foram defendidos em Programas de Pós-Graduação em Ciência da Informação divididos em oito linhas de pesquisa, dentre os quais 13 desses trabalhos (59\%) estão distribuídos em linhas relacionadas à Organização da Informação, área específica que estuda o Tratamento Temático da Informação, mais especificamente, políticas de indexação.

Contudo, verifica-se também produção de monografias sobre políticas de indexação em outros programas e linhas de pesquisa relacionados à gestão de organizações e tecnologias, mostrando que essa temática é pertinente não somente à organização da informação e que pode ser estudada através de diferentes abordagens por conta de envolver variados fatores, tanto em nível operacional e tecnológico quanto em nível de gestão. Esse fato pode ser constatado ao observar que as Instituições UNESP, UFPB e UFPE apresentam trabalhos sobre políticas de indexação em linhas de pesquisas diferentes (Quadro 4).

Quadro 4 - Distribuição das Teses (T) e Dissertações (D) por Programas de Pós-Graduação e Linhas de Pesquisas

\begin{tabular}{|c|c|c|c|}
\hline $\begin{array}{c}\text { Programas de Pós- } \\
\text { Graduação }\end{array}$ & Linhas de pesquisas & $T / D$ & Valor (\%) \\
\hline \multirow{6}{*}{$\begin{array}{l}\text { Ciência da } \\
\text { Informação }\end{array}$} & Produção e Organização da Informação (UNESP) & 10 & \multirow{6}{*}{$\begin{array}{c}82 \% \\
(18 \mathrm{~T} / \mathrm{D})\end{array}$} \\
\hline & Informação e Tecnologia (UNESP) & 1 & \\
\hline & $\begin{array}{l}\text { Memória, Organização, Acesso e Uso da Informação } \\
\text { (UFPB) }\end{array}$ & 2 & \\
\hline & Comunicação e visualização da memória (UFPE) & 1 & \\
\hline & Memória da Informação Científica e Tecnológica (UFPE) & 1 & \\
\hline & Políticas e Tecnologias da Informação (UFBA) & 1 & \\
\hline
\end{tabular}




\begin{tabular}{|c|c|c|c|}
\hline & Organização da Informação (UnB) & 1 & \\
\hline & Cultura e Informação (USP) & 1 & \\
\hline $\begin{array}{l}\text { Gestão em } \\
\text { Organizações } \\
\text { Aprendentes }\end{array}$ & $\begin{array}{l}\text { Gestão de projetos educativos e tecnologias emergentes } \\
\text { (UFPB) }\end{array}$ & 1 & $4,5 \%$ \\
\hline $\begin{array}{l}\text { Ciência, Tecnologia } \\
\text { e Sociedade }\end{array}$ & Gestão tecnológica e sociedade sustentável (UFSCar) & 1 & $4,5 \%$ \\
\hline Biblioteconomia & Organização e Representação do Conhecimento (Unirio) & 1 & $4,5 \%$ \\
\hline $\begin{array}{l}\text { Gestão da } \\
\text { Informação }\end{array}$ & Gestão de Unidades de Informação (UDESC) & 1 & $4,5 \%$ \\
\hline Total: $\mathbf{5}$ & 12 & 22 & $100 \%$ \\
\hline
\end{tabular}

Fonte: Elaborado pelas autoras (2017)

Os resultados dos indicadores bibliométricos apresentam, também, que, das 22 monografias, 10 (45\%), concentradas na UNESP, campus Marília, foram orientadas pela pesquisadora Mariângela Spotti Lopes Fujita, nos respectivos anos: 2004, 2008, 2011, 2012, 2014, 2015 e 2016, sendo que nos anos de 2008, 2012 e 2014 a referida professora orientou duas monografias em cada ano com o tema política de indexação (Quadro 5). Além dela, o pesquisador Edberto Ferneda orientou dois trabalhos (9\%), um na UNESP em 2014 e outro na UFPB em 2015. Os demais trabalhos foram orientados por apenas um profissional, distribuídos em diferentes instituições do país em anos variados, conforme pode ser observado no quadro 5.

Quadro 5 - Distribuição das Teses e Dissertações por Orientadores

\begin{tabular}{|c|c|c|c|c|}
\hline Orientadores & $\begin{array}{c}\text { Teses e } \\
\text { Dissertações }\end{array}$ & $\begin{array}{c}\text { Valor } \\
\text { (\%) }\end{array}$ & Instituições & Ano \\
\hline Mariângela Spotti L. Fujita & 10 & $45 \%$ & UNESP & $\begin{array}{c}2004,2008(2), 2011,2012 \\
(2), 2014(2), 2015 \text { e 2016 }\end{array}$ \\
\hline Edberto Ferneda & 2 & $9 \%$ & UNESP (1) & 2014 \\
\cline { 4 - 5 } & 1 & UFPB (1) & 2015 \\
\hline Ana Paula O. Villalobos & 1 & $4,6 \%$ & UDESC & 2015 \\
\hline Ana Maria Pereira & 1 & $4,6 \%$ & UFPB & 2016 \\
\hline Dulce Amélia de B. Neves & 1 & $4,6 \%$ & UnB & 2012 \\
\hline Dulce Maria Baptista & 1 & $4,6 \%$ & UFPE & 2013 \\
\hline Fabio Assis Pinho & 1 & $4,6 \%$ & UFPB & 2012 \\
\hline Guilherme Ataíde Dias & 1 & UFBA & 2013 \\
\hline
\end{tabular}




\begin{tabular}{|c|c|c|c|c|}
\hline Johanna Wilhelmina Smit & 1 & $4,6 \%$ & USP & 2009 \\
\hline Miriam Gontijo de Moraes & 1 & $4,6 \%$ & UNIRIO & 2016 \\
\hline Renato Fernandes Corrêa & 1 & $4,6 \%$ & UFPE & 2014 \\
\hline Vera Regina C. Boccato & 1 & $4,6 \%$ & UFSCar & \\
\hline Total & $\mathbf{2 2}$ & $\mathbf{1 0 0 \%}$ & & \\
\hline
\end{tabular}

Fonte: Elaborada pelas autoras (2017)

A pesquisadora Mariângela Fujita tem contribuído fortemente para os estudos de política de indexação em âmbito nacional. Docente e pesquisadora ligada a Faculdade de Filosofia e Ciências do Departamento de Ciência da Informação da UNESP Júlio de Mesquita Filho, Fujita tem desenvolvido e coordenado projetos de pesquisa sobre a temática; realizado atividades de ensino, pesquisa e extensão com enfoque na indexação e linguagens de indexação; orientado inúmeros alunos de mestrado e doutorado com temas englobando a indexação, análise de assunto, catalogação de assunto; bem como tem gerado uma larga produção científica sobre a temática política de indexação (FUJITA, 2017). Esses fatos, de certa forma, justificam tanto o número de monografias orientadas por Fujita quanto a concentração de estudos sobre política de indexação na UNESP (Tabela 2).

Apesar da concentração de monografias orientadas por apenas um pesquisador, no caso Fujita, verifica-se uma dispersão do tema em outras instituições com orientações de outros pesquisadores, o que de certa forma contribui para uma análise de diferentes perspectivas sobre o tema política de indexação em variados contextos.

\section{Considerações finais}

Ao apresentar um panorama das pesquisas sobre política de indexação a fim de conhecer a situação atual dos estudos a respeito do tema, pretendeu-se com esta pesquisa incrementar o debate sobre os estudos de Tratamento Temático da Informação, mais especificamente para estudos sobre políticas de indexação, bem como contribuir para que novos pesquisadores se interessem em pesquisar sobre a temática em questão.

Dessa forma, os resultados evidenciam poucas publicações relativas à temática, tendo sido recuperadas somente 22 monografias no Banco de Teses e Dissertações da CAPES. Contudo verifica-se que a produção sobre o tema está crescendo gradativamente nos últimos anos, principalmente a partir de 2012.

Dos trabalhos existentes, a maior parte está em nível de mestrado, com $86 \%$ de dissertações e apenas $14 \%$ de teses de doutorado, sendo a maioria concentrada na região Sudeste (63\%), precisamente na Instituição UNESP (50\%). 
Verifica-se também que os trabalhos são defendidos predominantemente em Programas de Pós-Graduação em Ciência da Informação (82\%), em linhas de pesquisas denominadas Organização da Informação (59\%), com 45\% destes trabalhos orientados por uma única pessoa, Mariângela Fujita.

Diante disso, constata-se que há necessidade de mais pesquisas e discussões sobre o tema políticas de indexação em diferentes instituições e realidades para que outros contextos e experiências possam ser retratados, ampliando dessa forma o quadro deste tema por meio de um estudo comparativo.

Portanto, a produção científica sobre políticas de indexação ainda caminha a passos estreitos em território brasileiro, sendo importante a elaboração de novos estudos sobre o tema e outras investigações para explorar e descrever, em escala maior, o cenário nacional sobre essa produção, visto que este estudo foi efetivado somente no Banco de Teses $e$ Dissertações da CAPES.

Outro aspecto a ser destacado é a relevância dos estudos bibliométricos para compreensão do desenvolvimento de determinadas áreas e temáticas, de modo que, neste estudo, a partir da análise de indicadores bibliométricos de teses e dissertações, foi possível ampliar um pouco mais o conhecimento sobre a temática política de indexação. Contudo sugere-se a utilização de outros indicadores bibliométricos para análise mais extensa sobre o tema.

\section{Referências}

ARAÚJO, C. A. Bibliometria: evolução histórica e questões atuais. Em questão, Porto Alegre, v. 12, n. 1, p. 11-32, jan./jun., 2006. Disponível em: http://seer.ufrgs.br/index.php/EmQuestao/article/view/16/5 Acesso em: 22 maio 2018.

ASSOCIAÇÃO BRASILEIRA DE NORMAS TÉCNICAS. NBR 12676: Métodos para análise de documentos - determinação de seus assuntos e seleção de termos de indexação. Rio de Janeiro, 1992.

BELLO, S. F. et al. Indicadores bibliométricos da produção científica sobre transtornos de aprendizagem na base de dados Scielo. In: HAYASHI, M. C. P. I; FARIA, L. I. L. de; HAYASHI, C. R. M. (Orgs.). Bibliometria e cientometria: estudos temáticos. São Carlos: Pedro \& João Editores, 2013. p. 195-208.

BENCHIMOL, A. Resgate e ressignificação da pesquisa no Museu Paraense Emílio Goeldi: presença e permanência de cientistas estrangeiros (1894-1914) na produção científica de autores atuais (1991-2010). 179 f. Tese (Doutorado em Ciência da Informação) - Programa de Pós-Graduação em Ciência da Informação, Instituto Brasileiro de Informação em Ciência e Tecnologia; Universidade Federal do Rio de Janeiro, Rio de Janeiro, 2015. Disponível em: 
http://repositorio.ibict.br/bitstream/123456789/847/1/Tese\%20Alegria\%20Benchimol\%20.pdf Acesso em: 20 out. 2017.

CAPES. Como funciona o banco de Teses da CAPES? 2010. Disponível em: http://www.capes.gov.br/acessoainformacao/perguntas-frequentes/periodicos/3571-comofunciona-o-banco-de-teses Acesso em: 15 out. 2017.

CAPES. Catálogo de Teses e Dissertações. Histórico e evolução. 2017b. Disponível em: http://sdi.capes.gov.br/banco-de-teses/02 bt sobre.html Acesso em: 15 out. 2017.

CAPES. Cursos recomendados e reconhecidos. 2017c. Disponível em: https://sucupira.capes.gov.br/sucupira/public/consultas/coleta/programa/quantitativos/quan titativoles.jsf?areaAvaliacao=31\&areaConhecimento=60700009 Acesso em: 30 out. 2017.

CAPES. História e missão. 2017a. Disponível em: http://www.capes.gov.br/historia-e-missao Acesso em: 15 out. 2017.

CARNEIRO, M. V. Diretrizes para uma política de indexação. Revista da Escola de Biblioteconomia da UFMG, Belo Horizonte, v. 14, n. 2, p. 221-241, set. 1985. Disponível em: http://www.brapci.inf.br/index.php/article/view/0000002649/79128bbbadf4b0d86344e6c75e a8a15d Acesso em: 18 maio 2016.

CAVALCANTI, C. R. Indexação. Estudos avançados em Biblioteconomia e Ciência da Informação. Brasília, DF: ABDF, v. 1, p. 211-233, 1982.

DAL' EVEDOVE, P. R.; FUJITA, M. S. L. Proposta de diretrizes para elaboração de política de indexação em bibliotecas universitárias: um estudo sociocultural com protocolo verbal. SCIRE, Zaragoza, v. 23, p. 13-23, $2017 . \quad$ Disponível em: https://ibersid.eu/ojs/index.php/scire/article/viewFile/4352/3875 Acesso em: 07 jan. 2018.

DIAS, E. W.; NAVES, M. M. L. Análise de assunto: teoria e prática. 2. ed. Brasília, DF: Briquet de Lemos/Livro, 2013.

FOSKETT, A. C. A abordagem temática da informação. São Paulo: Polígono; Brasília: UnB, 1973.

FUJITA, M. S. L. A identificação de conceitos no processo de análise de assunto para indexação. Revista Digital de Biblioteconomia e Ciência da Informação, Campinas, v. 1, n. 1, p. 60-90, jul./dez. 2003.2 Disponível em: https://periodicos.sbu.unicamp.br/ojs/index.php/rdbci/article/view/2089 Acesso: em: 07 jan. 2018.

FUJITA, M. S. L. A política de indexação para representação e recuperação da informação. In: GIL LEIVA, I.; FUJITA, M. S. L. (Org.). Política de indexação. São Paulo: Cultura Acadêmica; Marília: Oficina Universitária, 2012. Disponível em: https://www.marilia.unesp.br/Home/Publicacoes/politica-de-indexacao ebook.pdf Acesso em: 03 jan. 2017.

FUJITA, M. S. L. Currículo do sistema Currículo Lattes. [Brasília], 06 nov. 2017. Disponível em: http://lattes.cnpq.br/6530346906709462 Acesso em: 06 nov. 2017. 
FUJITA, M. S. L. Política de indexação para bibliotecas: funções e finalidades. In: FUJITA, M. S. L. (Org.). Política de indexação para bibliotecas: elaboração, avaliação e implantação. Marília: Oficina Universitária; São Paulo: Cultura Acadêmica, 2016. Disponível em: https://www.marilia.unesp.br/Home/Publicacoes/politicas-de-indexacao-parabibliotecas ebook.pdf Acesso em: 22 mar. 2016.

FUJITA, M. S. L._Política de indexação para bibliotecas: elaboração, avaliação e implantação. 1. ed. Marília; São Paulo: Oficina Universitária; Cultura Acadêmica, 2016. v. 1. 142 p.

FUJITA, M. S. L.: GIL LEIVA, I. Políticas de indexação latino-americanas. Ibersid, Zaragoza, v. 3, p. 155-162, 2009. Disponível em: https://www.ibersid.eu/ojs/index.php/ibersid/article/download/3735/3496 Acesso em: 17 dez. 2018.

FUJITA, M. S. L.; SANTOS, L. B. P. dos. Política de indexação em bibliotecas universitárias: estudo diagnóstico e analítico com pesquisa participante. TransInformação, Campinas, n. 28, v. 1, p. 59-76, jan./abr., 2016. Disponível: http://scielo.br/pdf/tinf/v28n1/0103-3786-tinf-2801-00059.pdf Acesso em: 11 set. 2017.

GONÇALVES, M. C. A indexação em catálogo on-line em bibliotecas universitárias na percepção de usuários integrantes de grupos de pesquisa: uma contribuição ao desenvolvimento de política de indexação na rede de bibliotecas da UNESP/ Maria Carolina Gonçalves. 2008. 148 f. Dissertação (Mestrado em Ciência da Informação), Faculdade de Filosofia e Ciências, Universidade Estadual Paulista, Marília, 2008. Disponível em: https://repositorio.unesp.br/bitstream/handle/11449/93698/goncalves mc me mar.pdf?seq uence=1\&isAllowed=y Acesso em: 29 mar. 2016.

GUIM, V.; FUJITA, M. S. L. Política De Indexação e Linguagens Documentárias nas Bibliotecas Escolares. Brazilian Journal of Information Science, v. 10, p. 120-125, 2016. Disponível em: http://www2.marilia.unesp.br/revistas/index.php/bjis/article/view/6164/4274 Acesso em: 07 jan. 2018.

GUIMARÃES, V. A. L. et al. Traçado bibliométricos do campo da Sociologia da Ciência em dissertações e teses no Brasil. In: HAYASHI, M. C. P. I; MUGNAINI, R.; HAYASHI, C. R. M. (Org.). Bibliometria e cientometria: metodologias e aplicações. São Carlos: Pedro \& João Editores, 2013.

HAYASHI, M. C. P. I; FARIA, L. I. L. de; HAYASHI, C. R. M. (Org.). Bibliometria e cientometria: estudos temáticos. São Carlos: Pedro \& João Editores, 2013.

LOUSADA, M. et al. Políticas de indexação no âmbito da gestão do conhecimento

Organizacional. Informação \& Sociedade: Estudos, João Pessoa, v.21, n.1, p. 191-202, jan./abr. 2011. Disponível em: http://www.periodicos.ufpb.br/ojs2/index.php/ies/article/view/4136 Acesso em: 11 set. 2017.

MALAMAN, N. G.; SAMPAIO, S. F.; SOUZA, M. B. B. de. Estado da arte acerca do processo de trabalho em Enfermagem. In: HAYASHI, M. C. P. I; FARIA, L. I. L. de; HAYASHI, C. R. M. (Org.). Bibliometria e cientometria: estudos temáticos. São Carlos: Pedro \& João Editores, 2013. p. 159-168.

MARICATO, J. de M.; NORONHA, D. P. Indicadores bibliométricos e cientométricos em CT\&I: apontamentos históricos, metodológicos e tendências de aplicação. In: HAYASHI, M. C. P. I; 
LETA, J. (Orgs.). Bibliometria e cientometria: reflexões teóricas e interfaces. São Carlos: Pedro \& João Editores, 2013. p. 59-82.

MEADOWS, A. J. A comunicação científica. Brasília, DF: Briquet de Lemos, Livros, 1999.

MUELLER, S. P. M.; PASSOS, E. J. L. As questões da comunicação científica e a ciência da informação. In: MUELLER, Suzana P. M.; PASSOS, Edilenice J. L. (Org.). Comunicação científica. Brasília: Ciência da Informação, 2000. p. 13-22. Disponível em: http://repositorio.unb.br/handle/10482/1444 Acesso em: 21 set. 2017.

NUNES, C. O. Algumas considerações acerca da ausência de políticas de indexação em bibliotecas brasileiras. Biblos: Revista do Instituto de Ciências Humanas e da Informação, Rio Grande, v. 16, p. 55-61, 2004. Disponível em: http://www.seer.furg.br/index.php/biblos/article/view/411 Acesso em: 28 abr. 2016.

PEREIRA, M. A.; FERREIRA JÚNIOR, A.; HAYASHI, M. C. P. I. Colégios jesuíticos no Brasil Colonial: análise bibliométrica de teses e dissertações. In: HAYASHI, M. C. P. I; MUGNAINI, R.; HAYASHI, C. R. M. (Org.). Bibliometria e cientometria: metodologias e aplicações. São Carlos: Pedro \& João Editores, 2013.

PINHEIRO, L. V. R. Medidas de consistência na indexação: interconsistência. Ciência da Informação, Rio de Janeiro, n. 7, v. 2, p. 109-114, 1978. Disponível em: http://revista.ibict.br/ciinf/article/view/116 Acesso em: 18 jan. 2018.

PINHEIRO, L. V. R. Evolução da comunicação científica até as redes eletrônicas e o periódico como instrumento central deste processo. In: CONFERÊNCIA IBERO-AMERICANA DE PUBLICAÇÕES ELETRÔNICAS NO CONTEXTO DA COMUNICAÇÃO CIENTÍFICA, 1. Brasília, Anais... Campo Grande: Editora UNIDERP, 2006, v. 1. p. 27-38.

PIOVEZAN, L. B. Avaliação da indexação em catálogos de bibliotecas universitárias por meio da recuperação da informação. 2015. 103f. Dissertação (Mestrado em Ciência da Informação) Faculdade de Filosofia e Ciências, Universidade Estadual Paulista, Marília, 2015. Disponível em: http://repositorio.unesp.br/handle/11449/126586 Acesso em: 15 maio 2016.

PIZZANI, L. et al. Estudo bibliométrico da produção científica em prematuridade na BVS/Bireme. In: HAYASHI, M. C. P. I; FARIA, L. I. L. de; HAYASHI, C. R. M. (Org.). Bibliometria e cientometria: estudos temáticos. São Carlos: Pedro \& João Editores, 2013. p. 169-182.

PRODANOV, C. C.; FREITAS, E. C. de. Metodologia do trabalho científico: métodos e técnicas da pesquisa e do trabalho acadêmico. 2. ed. Novo Hamburgo: Feevale, 2013. Disponível em: http://www.feevale.br/Comum/midias/8807f05a-14d0-4d5b-b1ad-1538f3aef538/Ebook\%20Metodologia\%20do\%20Trabalho\%20Cientifico.pdf Acesso em: 15 set. 2017.

REDIGOLO, F. M. O processo de análise de assunto na catalogação de documentos: a perspectiva sociocognitiva do catalogador em contexto de Biblioteca Universitária. 2010. 176f. Dissertação (Mestrado em Ciência da Informação) - Faculdade de Filosofia e Ciências, Universidade Estadual Paulista, Marília, 2010. Disponível em: https://repositorio.unesp.br/bitstream/handle/11449/93668/redigolo fm me mar.pdf?seque nce=1\&isAllowed=y Acesso em: 20 set. 2017.

REDIGOLO, F. M. et al._Elementos de política de indexação em biblioteca universitária da área médica. Scire, Zaragoza, v. 18, p. 75-86, 2012 . Disponível em: 
https://repositorio.unesp.br/bitstream/handle/11449/73998/2-s2.0-

84882967504.pdf?sequence=1\&isAllowed=y Acesso em 07 jan. 2018.

ROBREDO, J. Documentação de hoje e de amanhã. Brasília, DF: Associação Bibliotecários do Distrito Federal, 1978.

RUBI, M. P. Política de indexação na perspectiva do conhecimento organizacional. 2004. 136 f. Dissertação (Mestrado em Ciência da Informação) - Faculdade de Filosofia e Ciências, Universidade Estadual Paulista, Marília, 2004. Disponível em: https://www.marilia.unesp.br/Home/Pos-

Graduacao/Cienciadalnformacao/Dissertacoes/rubi mp me mar.pdf Acesso em: 16 nov. 2016.

RUBI, M. P. Os princípios da política de indexação na análise de assunto para catalogação: especificidade, exaustividade, revocação e precisão na perspectiva dos catalogadores e usuários. In: FUJITA, Mariângela Spotti Lopes (Org.). A indexação de livros: a percepção de catalogadores e usuários de bibliotecas universitárias. Um estudo de observação do contexto sociocognitivo com protocolos verbais. São Paulo: Cultura Acadêmica, 2009. Capítulo 4, p. 8193. Disponível em: http://books.scielo.org/id/wcvbc/pdf/boccato-9788579830150.pdf Acesso em 12 nov. 2017.

RUBI, M. P.; FUJITA, M. S. L._O ensino de procedimentos de política de indexação na perspectiva do conhecimento organizacional: uma proposta de programa para a educação à distância do bibliotecário. Perspectivas em Ciência da Informação, Belo Horizonte, v. 11, n.1, p. 1-16, 2006. Disponível em: http://www.scielo.br/pdf/pci/v11n1/v11n1a05.pdf Acesso em 07 jan. 2018.

RUBI, M. P.; FUJITA, M. S. L._Política de indexação na catalogação de assunto em bibliotecas universitárias: a visão sociocognitiva da atuação profissional com protocolo verbal. Revista Digital de Biblioteconomia e Ciência da Informação, v. 7, p. 118-150, 2010. Disponível em: https://periodicos.sbu.unicamp.br/ojs/index.php/rdbci/article/view/1960/2081 Acesso em 30 out. 2017.

RUBI, M. P.; FUJITA, M. S. L.; BOCCATTO, V. R. C. Del conocimiento tácito al explícito: elaboración de un manual de política de indización en bibliotecas universitarias. Scire, Zaragoza, v. 18, p. 67-74, $2012 . \quad$ Disponível em: https://www.ibersid.eu/ojs/index.php/scire/article/view/3948/3708 Acesso em: 30 out. 2018.

STUMPF, I. R. C. Revisão pelos pares: do tradicional ao inovador. In: CONFERÊNCIA IBEROAMERICANA DE PUBLICAÇÕES ELETRÔNICAS NO CONTEXTO DA COMUNICAÇÃO CIENTÍFICA, 1., 2006, Brasília. Anais...Campo Grande: UNIDERP, 2006.

UNIVERSIDADE ESTADUAL PAULISTA. Faculdade de Filosofia e Ciências, campus Marília. Programa de Pós-Graduação em Ciência da Informação. Linhas de Pesquisa. 2017. Disponível em: $\quad$ https://www.marilia.unesp.br/\#!/pos-graduacao/mestrado-e-doutorado/ciencia-dainformacao/linhas-de-pesquisa/ Acesso em 30 out. 2017.

UNISIST. Princípios de indexação. Revista da Escola de Biblioteconomia da UFMG, Belo Horizonte, v. 10, n. 1, p. 83-94, 1981. Disponível em: http://brapci.inf.br/index.php/article/view/0000002687/69bd53c042cbf900f8004553c134b6b 2 Acesso em: 15 jan. 2018. 